\title{
Waves of potentiality: Some thoughts on database narratives and the digital dissemination of audio-visual practice research
}

\author{
Tony Dowmunt
}

I'm currently completing the dissemination stage of my practice/research (P/R) AHRC Fellowship in the Creative and Performing Arts. The 'outcomes' of the project include a linear finished film, some text in the form of articles, along with a selection of other material, including rushes, stills and more text (both academic writing, article journals and more speculative/creative material).

At the moment I'm trying to decide on the most useful way to present and circulate this material so as to make it available for peer review, and to make my 'research journey' available to others. My understanding of peer review is that it's not just a process of making and receiving judgements about whether the artefacts being reviewed are any good or not, it is most useful when it includes an analysis of how, and to what extent, the artefacts, and, crucially, the research processes that led to them, 'embody new knowledge, it's an assessment of the journey as well as (and maybe more crucially than) the point of arrival. So this paper is about the current state of my search for a way to present both of these elements - the processes and the products.

My underlying question is: what presentation methods will work best to enable (this particular) moving image work and its contextual material, to communicate to other researchers and generate new knowledge? I think it's now possible to move beyond the familiar text/film polarity - the conflict over whether (or to what extent) a film needs text accompaniment to make it a bona fide research outcome. I'm working on the assumption that 'new'/digital/ media have (at least in theory) made the distinction redundant. At a very literal level everything's now coded in 0 s \& 1 s, so all academic practitioners are involved in digital text production - whether in Word, Powerpoint, Final Cut Pro or Protools. Moving pictures, sounds, text and stills can be included in the same artefact, and presented on screens. So digitisation liberates us to ask a 
more basic and useful question: what (for us as P/R practitioners in moving image) is the appropriate material form for an academic research outcome, given these technological developments?

Though I know that the current formal conventions of text-based academic research writing do not go unchallenged, their generic conventions (of, for instance, the 'literature review', or footnoting and referencing) have been in place and used for a long time. In contrast, what we as practice-researchers are currently seeking, is a radically new form of academic 'text/imageproduction' that can both fulfil the objective of making our research processes transparent to other researchers, but also, crucially, is able to convey the nuances and textures of work that has been originated (at least partially) through audio-visual (rather than text-print) media. 'New'/digital media clearly offer ways of doing that, and of course, it has recently become almost a mantra to say that digital media - and particularly DVD - will provide the tools that we as moving image practice researchers need to disseminate our researchii.

\section{A Whited Sepulchre:}

'If Sierra Leone is the white man's grave, it is certainly a whited sepulchre, very fair to look upon outside. However before long I shall have plenty of opportunity of seeing whether there is anything particularly foul within the fair exterior.'

So wrote my great-grandfather in his diary, on arriving as a young Lieutenant in the British Imperial Army in Sierra Leone in the 1880s. At the centre of my Fellowship research project is a video which draws on the stories of two journeys: my great-grandfather's account in his diaries of his posting to Sierra Leone, and my own video diary of a trip that I am made in December/January 2004-5, following in his footsteps but seeking a different understanding of Africa and of myself as a white Englishman. 


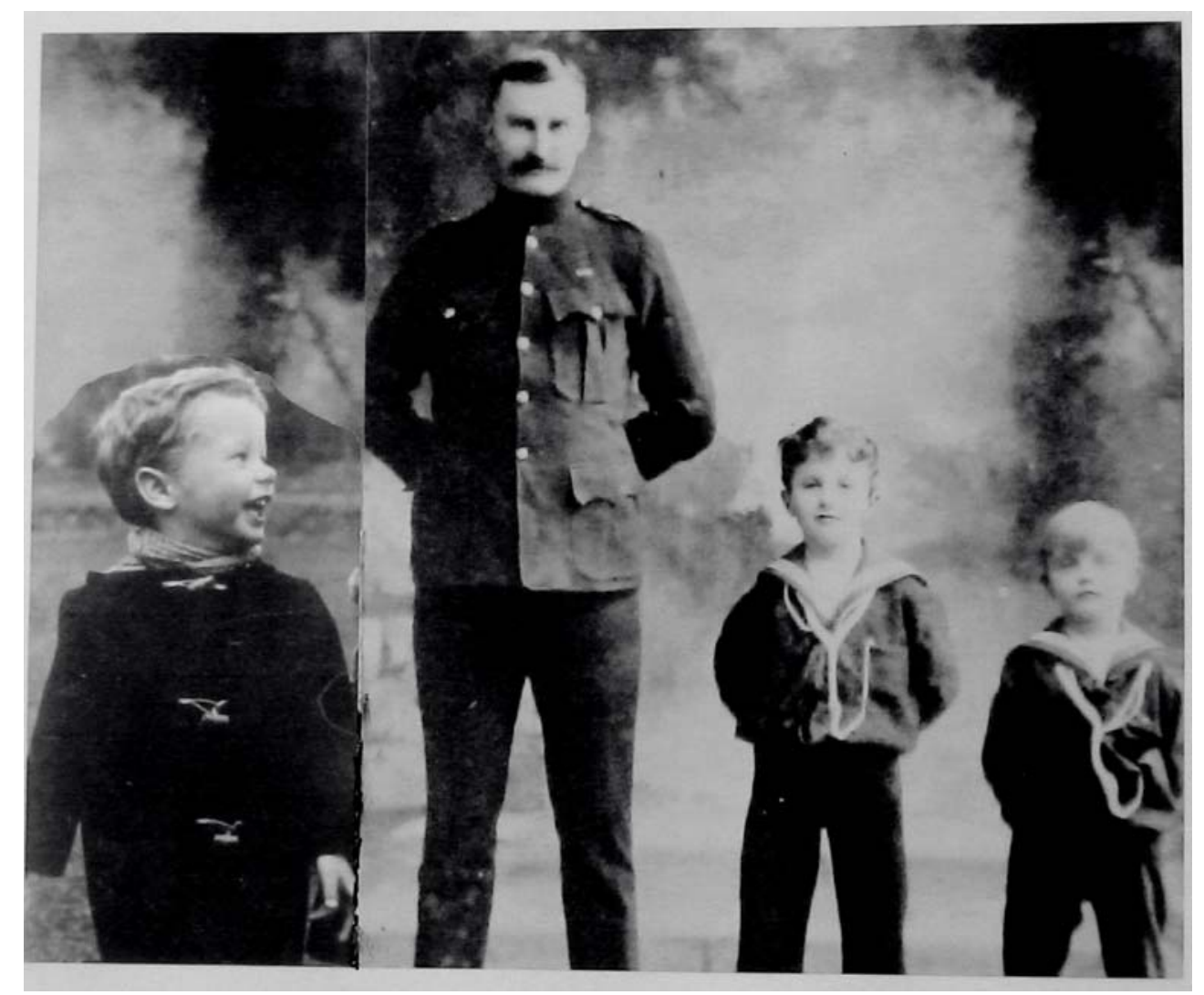

Fig1: Me in 1957, my great grandfather and his sons (my grandfather on the right) in 1898.

I'm using these contrasting autobiographical discourses (stretched between two historically situated, divergent but connected subjectivities) to call into question some of the more traditional aspects of both documentary film and the autobiographical form: for instance, to ask whether and how the more personal/confessional 'video diary' mode contrasts with the more formal, 'objective' tone of the Victorian written diaries ${ }^{\mathrm{iii}}$. Part of this research project is also the attempt to discover aesthetic strategies within (and beyond) the 'video diary' mode that will enable the piece to reveal and represent complex issues of identity formation - my own and my great-grandfather's. I have experimented with a video diary form that is about history, as well as the present, and that uses the confessional immediacy and 'authenticity' of the video diary, in a context which to some extent also calls it into question, and reveals it as another 'performance of the self'. 
As I worked on editing the film, I concluded (a little reluctantly) that the Whited Sepulchre video is not an entirely 'self-explanatory artefact' ${ }^{\text {iv }}$ : I'm not expecting it to be able to stand on its own as a research outcome, without any textual and other contextual material. It turns out (to my regret!) that I'm not Dziga Vertov or Jean-Luc Godard, both of whose work is sometimes cited as offering possible models of 'stand-alone' or self-explanatory audio-visual research outcomes. As a filmmaker I like linear flow, and tend to go for narrative coherence, atmosphere and emotion over more cognitive or 'deconstructed' qualities. However my understanding as an 'academic' is that to qualify as a 'research outcome' a film on its own would need to be visibly and audibly interrogating itself, to display it's own meta-narrative alongside, or within, its narrative ${ }^{v}$.

I'm not sure of the extent to which the Whited Sepulchre video does this. Part of my research project was an attempt to question - and to experiment with undermining in practice - conventional notions and models of documentary authority. In relation to autobiographical filmmaking a key site for this experimentation has to be the 'character' and 'voice' of the filmmaker - in other words, the 'authority' of the 'author'. Because of my tendency to go for narrative flow (and because I'm now still so close to the project) I'm uncertain as to the degree that the film really questions, undermines or de-constructs the coherence of my 'subject position' as author and autobiographical 'subject' - for instance how much it conveys and interrogates my 'unreliability' as the narrator of the film, or, in other words, provides a 'meta-narrative' on the issue of 'author/ity'. My voice is (literally) present in the film in my to-camera diary pieces and in the voiceover recorded later, at the time of editing. In early edits of the piece I also performed my great-grandfather reading from his own diaries, but have since abandoned this strategy as too confusing for the audience, and am currently using an actor. Whether this now conveys multivocal deconstruction, or slips back into univocal authoritativeness, and so to what extent the film embodies its own meta-narrative on the issue of 'voice', I'm not sure and perhaps is for others to assess anyway. 


\section{Database/Narrative:}

In thinking through the ways in which digital dissemination might help me to illuminate the 'meta-narrative' in A Whited Sepulchre, I've been making use of Lev Manovitch's work, which, interestingly for moving image P/R, posits a strong connection between film and 'new' media, for instance when he says:

.. cinematic ways of seeing the world, of structuring time, of narrating a story, of linking one experience to the next, have become the basic means by which computer users access and interact with all cultural data (Manovitch 2001: 78).

In fact he sees the processes of filmmaking and new media as being inextricably intertwined: 'we can think of all the material accumulated during shooting as forming a database ..' (Manovitch 2001: 237). So I started thinking about my material as a database of digital 'assets' - as well as the components of a finished, linear and coherent, film.

Along with many other P/R filmmakers, I'm looking to forms of digital dissemination - specifically DVD and/or the web - to lend more reflexivity, more self-interrogation, to the process of sharing my research than will be available in the film on its own - to give it what Manovitch calls a 'new metarealism'. He describes how 'the systematic 'auto-deconstruction' performed by computer objects, applications, interfaces, and hardware' produces this 'new metarealism' which 'is based on oscillation between illusion and its destruction, between immersing a viewer in illusion and directly addressing her'(Manovitch 2001: 208). There is a whiff of 'technological determinism' here which I'm not comfortable with: I see this 'new metarealism' as a socially situated, discursive possibility enabled by computers, not a product of the machines or software themselves. Nevertheless his thesis is useful to me in the context of this paper, in that it suggests that there's something about the 'language of new media' which makes it inherently selfreflexive, or allows it to interrogate itself, and that this something derives from the way in which new media uses the database - rather than narrative - as its 'key form of cultural expression'(2001: 208). 
As Marsha Kinder points out, Manovitch sees database structures as being in 'combative opposition to narrative'(Kinder 2003: 348), because he describes them as 'two competing imaginations, two basic creative impulses, two essential responses to the world' (Manovitch 2001: 233). One example of this database/narrative polarity which Manovitch cites is that of the filmmaker Peter Greenaway's installations, made in the 1990s as part of his move away from the linear medium of film. Manovitch suggests: 'This move can be read as a desire to create a database in its most pure form - as a set of elements not ordered in any way. If the elements exist in one dimension (the time of the film, the list on a page) they will inevitably be ordered. So the only way to create a pure database is to spatialise it, distributing the elements in space' (Manovitch 2001: 238).

I'm not convinced that this way of presenting material - his 'pure database' - is not itself ordered, albeit in a different way - or is even necessarily antinarrative. Manovitch himself defines a database 'as a structured collection of data' (2001: 218). It seems like a database is a different way of 'telling a story', of structuring the material so it is open to understanding or analysis but of course in a way that linear narrative is incapable of doing. Manovitch's use of the spatial metaphor reminds me of a number of moving image P/R projects at use installation techniques: for instance the installation version of Cahal McLaughlin's Belfast project 'Inside Stories' (2004), in which the 'spatialising' of the elements - the distribution of the 3 screens in the exhibition space - the Republican on one side, Billy Hutchinson on the other, the Prison warder in the middle - is itself integral to the overall 'story' and structure of the piece - or John Adams' 4 screens and assorted loudspeakers in 'Hindsight' (2004). The 'spatialisation' in both these cases are clearly alternative ways of narrating their themes and ordering their material.

Kinder also takes issue with Manovitch's polarised view of database and narrative: 
I see database and narrative as two compatible structures whose combination is crucial to the expansion of new media, since all narratives are constructed by selecting items from databases (that usually remain hidden) and then combining these items to make a particular story .. the process of retrieval necessarily involves ideology and desire: where we are permitted to look and what we hope to find (Kinder 2003: 348-349).

'Where we are permitted to look' in documentaries and 'what we hope to find' there seem to me to be key issues for documentary research, the kinds of questions we would expect to be explored in documentary P/R work. So it's interesting that Kinder includes a number of documentaries in her list of films which use the structure of what she calls 'database narrative', when these two structures come together: films like Chris Marker's Sans Soleil (1983) , Agnes Varda's The Gleaners and I(2000)and Peter Forgacs's Maelstrom (1998) and The Danube Exodus (1997). For her, 'database narrative' refers to

narratives whose structure exposes or thematizes the dual processes of selection and combination that lie at the heart of all stories and that are crucial to language: the selection of particular data (characters, images, sounds, events) from a series of databases or paradigms, which are then combined to generate specific tales .. Such narratives reveal the arbitrariness of the particular choices made, and the possibility of making other combinations which would create alternative stories. By always suggesting virtuality and the wave of potentialities linked to the uncertainty principle, such narratives inevitably raise meta-narrative issues (Kinder 2002: 3).

If the database structure itself does indeed 'inevitably' raise 'meta-narrative issues', it is clearly an extremely useful tool for P/R work (if we accept that such work needs to be seen to be interrogating itself and displaying it's own meta-narrative). We already have a potential 'new media' example of this kind of (meta-)narrative in Chris Marker's CD-ROM Immemory (1998). Catherine Lupton talks about how

'The capabilities of the CD-Rom provide the ideal vehicle for Marker's virtual projection of his memory, since they enable him to draw together text and images in new, mobile, infinitely open-ended 
hypermedia constellations that transcend the existing models of both book and film' (2005: 210).

The implication is that Immemory could be a pre-cursor of the new form of academic 'text-production' that I was suggesting above we are seeking: neither a written text nor an audio-visual work, but something distinct and different, that combines useful elements of both.

\section{A deconstructed Whited Sepulchre:}

My contention is that is that surfing Kinder's 'wave of potentialities linked to the uncertainty principle', and so getting away from the 'one dimensional ordering' of linearity, does indeed open up spaces for reflexivity. There are obviously many elements of conventional, linear film language that actively work against reflection, that make a film unlikely to offer up an analysis of itself, that, in effect, hide its research history. Some techniques of storytelling and construction in both fiction and documentary lead an audience to a 'suspension of disbelief' (like, say, conventional continuity editing) and so hide or obscure the authorial choices that need, I would argue, to be more transparent and open for discussion in a 'stand-alone' P/R work. An example of this from the Whited Sepulchre film might be the 'journey/travel diary' structure that I used. This was determined in part by the circumstances of my African trip, but also borrows from many of the generic characteristics of this journey structure (for instance, setting out into the 'unknown', or reaching a destination as a psychic as well as geographic event), without necessarily making this borrowing particularly explicit or transparent.

However, the film is also a collage made up of material from a range of sources, including: 
- The two diaries: my great-grandfather's handwritten entries and my daily 'to-camera' pieces during my visit to Sierra Leone

- the actuality and travel footage I also shot during my visit

- and footage of my revisiting my old house in Engalnd, inherited by my mother from my great-grandfather, in which I was born

- Photographs of Sierra Leone contemporary to my greatgrandfather's time there

- A fictional home movie I made aged 13

- Documentary footage from 20 years ago of myself in a psychotherapy group.

In addition there is obviously a mountain of material that I have accumulated and worked on that didn't make it into, or anywhere near, the final film, including some articles and autobiographical writing, films and family photos. So there is plenty of potential here for the telling of alternative stories, in addition to the linear 'travel' film.

I have two basic needs from a digital presentation of my research project. The first is the relatively mundane one of wanting to be able, in effect, to provide the film with 'footnotes'. I initially assumed that DVD would be capable of providing the tools to achieve this, but practically it's been my experience that DVD is still a very cumbersome medium - it's difficult to get a lot of video data at high resolution on to one disc, and it's very complicated to move between different kinds of media - say a high resolution version of a film and a text PDF. This is something l'd like to able to do - an equivalent to footnoting in an academic article. For instance in the film, I quote - obviously selectively from my great-grandfather's diaries, often filming the page they come from, normally framing them quite tight, excluding a lot of surrounding text. I would like the DVD user to be able to refer to and explore a scan of the whole page 
or pages which I'm quoting. This is not just so they can see my primary source, the raw material of my research, but also because the contrast between the two (the source and my use of it) will be illuminating in relation to the larger theme of evidentiary status and function of manipulated 'documentary' material. In the film I - of course - use my great-grandfather's words to make a point, or aid the narrative, as evidence for my story and argument. By looking at the context of the quote in the whole page, the user will both be able examine my choices and to gauge the 'legitimacy' of my use of the diary, but also come to their own interpretation, and so begin to dismantle my construction of documentary evidence in the film. A similar point could be made about the Victorian photographs of Sierra Leone I use later in the film, or about the home movie film, of which I use about 2 minutes of extracts, but which runs for 8 minutes in its original version.

The second need I have of digital media is perhaps more experimental, and arises out of some of the more theoretical questions that underpin the project about the issue of authorship in autobiographical documentary film/video. My thinking around this issue is influencing the choice I have to make between disseminating the research on DVD and/or a website. At the moment I'm tending towards the web and DVD combined, partly because this will overcome the problems of combining text and video outlined above. I'm interested in the new ways are being developed of being able browse a web page while the DVD movie plays at full resolution in a window within it ${ }^{\mathrm{vi}}$.

Another obvious advantage of having a website associated with the film on DVD, is that of being able to add extra material, keeping a site up to date, changeable and fluid and. One of my aims is to be able to tell my research story autobiographically - naturally, because of the subject and orientation of the research (the place of the personal and subjective in documentary studies). However I also don't want to present the research outcomes as the product of a totally coherent and 'finished' self. Historically, because autobiography as a genre 
has been seen as promoting a view of the subject as universal, it has also underpinned the centrality of masculine - and , we may add, Western and middle-class - modes of subjectivity. (Anderson 2001: 3)

I clearly need to interrogate and undermine these generic tendencies, with their dependence on a coherent, unfragmented notion of a Western subject, if the project is to have the critical, anti-colonial edge I want it to. A website could provide some of this edge in that will enable the project to remain open ended:

Web sites never have to be complete: and they rarely are. They always grow .. All this further contributes to the anti-narrative logic of the Web. If new elements are being added over time, the result is a collection, not a story. Indeed, how can one keep a coherent narrative or any other development trajectory through the material if it keeps changing? (Manovitch 2001: 220-21)

The website - which will be a Wiki platform hosted at Goldsmiths - will hopefully become a place for me to get feedback and for others to enter the debate on the issues the project raises - a form of peer review, if you like. I will be then able to keep re-working my interpretation of the film and its surrounding material, making it clear that the work of memory and autobiography (and of the construction of the self) is one of continual revision, re-working the fragments. My 'self' cannot be fixed but is always in process within social relationships, in response to intervention by others and my own development and re-interpretations.

\section{The interpretation of dreams:}

Am I really ' $\mathrm{l}$ ' through to the very core of my being? Or do I, at my very heart, incorporate active originating forces which are not 'l' at all? (Frayn 2006: 6) 
Micheal Frayn asks this question in his discussion of how we are the 'authors' of our own dreams, but it serves me as a summary of my dilemma as a researcher into autobiographical filmmaking: how to 'author' a work and present the research context that surrounds its making at the same time as acknowledging and working with the necessarily partial and fragmented sense of my self that is doing the authoring. One way I attempt to do this in A Whited Sepulchre is through using extracts from to-camera video diary pieces in which I relate dreams I had during my trip to Sierra Leone. I hope they suggest the ways in which my particular, 'imperialist' family history resonates into the present, in ways I am only partly conscious of. Marsha Kinder describes dreams as

the ultimate model for interactive database narrative. For in dreams, we are nightly bombarded by a random firing of neural signals generated by the brain which the cerebral cortex must interpret. It performs this interpretive task by drawing selections from our internal databases of imagery, which contain virtually everything we have ever experienced and everything we have absorbed from our cultural dreampool, and we reshuffle these selections to generate new combinations that we narrativize when we awaken.(2002:10)

I kept my camcorder by my bed through out my stay in Sierra Leone, and used to do these bleary-eyed pieces to camera relating my dreams, on awakening. I think they do give some 


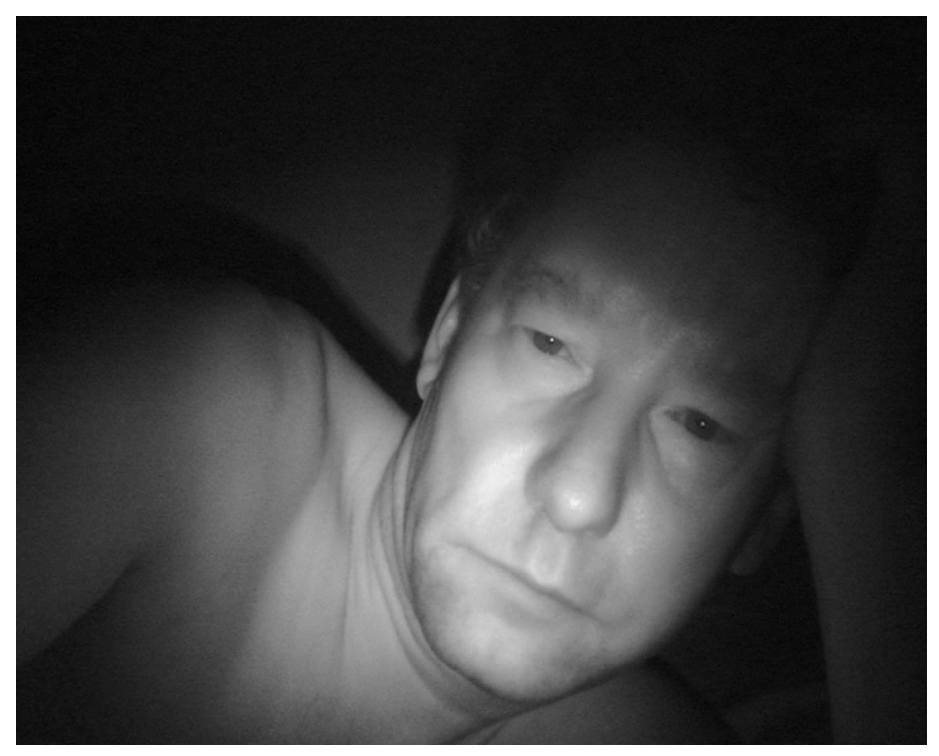

Fig 2: A Whited Sepulchre: telling

a dream

sense of a different, less 'conscious' self/author at work: however, only a small proportion of this material has found its way in to the finished film, of course carefully chosen and heavily edited to illuminate the psychic journey I am depicting in A Whited Sepulchre - my conscious 'interpretive task'. I'm happy to stand by these choices as a filmmaker, but I think that part of my job as a researcher, as I've said, is to provide a way for other researchers to be able to see behind the choices l've made, to open them up for scrutiny.

This will itself be a narrative process, of course, involving me in making more editorial choices. An added feature I am thinking about making for the website is a way for the site users to be able to access much more of this dream material than is visible in the film. I could segment my accounts of the dreams to individual sentences and tag them according to appropriate words, themes or feelings (eg 'fear', 'guilt', 'animals', 'family', 'mother') so that users will be able edit or re-shuffle their own versions of the material, to interact with my 'cultural dreampool', with less authorial intervention from me than there is in the linear film: an 'open-ended hypermedia constellation' of material from my psyche. vii

There are other options I am exploring, at the instigation of Sandra Guadenzi, a documentary maker who read a first draft of this paper, which would involve me in a greater surrendering of my authorial control. One of the things she 
suggested is that 'you could put some of your footage online in a collaborative film website. People will use and and add to your footage, and what will emerge is totally unknown ...'(Guadenzi 2006) She points out: 'This can be challenging and painful, and I believe one has to decide if it is worth it. A bit like going to the shrink and having your life torn apart'(ibid.).

Whether I'll find out that this is worth doing or not, I'm convinced that the many and varied ways of opening out a text that 'new' media offer will become indispensable techniques in the dissemination of audio visual P/R. Whatever I finally decide to do will appear on www.awhitedsepulchre.info later in 2007.

\section{Bibliography:}

Adams, J. (2004) Expanded Cinema Project: Hindsight University of Bristol

Anderson, L. (2001) Autobiography London: Routledge

Dowmunt, T. (2003) 'A WHITED SEPULCHRE: Autobiographical Film/Video as Practice Research' in The Journal of Media Practice (Volume 4, No 1)

Dowmunt, T. (2006) 'First Impressions/Video Confession' in Life Writing (Vol 2, No 2, 2005, pp 155-171)

Dowmunt, T. and Thomas, R. (2005) 'Supervising and examining practice-based PhDs in the moving image' in The Journal of Media Practice (Volume 6, No 2)

Forgacs, P. (1998) Maelstrom Amsterdam: Lumen Film

Forgacs, P. (1997) The Danube Exodus Amsterdam: Lumen Film

Frayn, M. (2006) While you are sleeping. Saturday September $9^{\text {th }} 2006$ London: Guardian Review (extract from Frayn, M.(2006) The Human Touch London: Faber and Faber)

Gaudenzi, S. (2006) Email conversation with me.

Kinder, M. (2003) 'Designing a Database Cinema', in Shaw, J and Weibel, P. (eds) Future Cinema: The Cinematic Imaginary after Film ZKM: Center for Art \& Media and Cambridge, MA: The MIT Press

Kinder, M. (2002) 'Hotspots, Avatars and Narrative Fileds Forever: Bunuel's Legacy for New Digital Media and Interactive Database Narrative' - available at www.filmquarterly.org/issue 5504 right.html (accessed 28/06/2006) 
Le Grice, M. (2001) Experimental Cinema in the Digital Age

Lupton, C. (2005) Chris Marker - Memories of the Future London: Reaktion Books

Manovitch, L. (2001) The Language of New Media Cambridge, Massachusetts: The MIT Press

McLaughlin, C. (2004) Inside Stories: Memories from the Maze and Long Kesh Prison' University of Ulster

RAE (2006a) RAE 2008 Panel criteria and working methods: Panel O http://www.rae.ac.uk/pubs/2006/01/byuoa.asp?u=0 (accessed 1/9/06)

Varda, A. (2000) The Gleaners and I (Les Glaneurs et la Glaneuse) Paris: Ciné Tamaris

i This being a key phrase in the current RAE documents (RAE 2006: 5))

ii See, for instance, an account of discussions at a symposium in 2004 at University of Westminster (Dowmunt and Thomas 2005: pp 122-3)

iii I've written about this contrast in Dowmunt 2006.

iv I discuss the issue of the 'self-explanatory artefact' at more length in Dowmunt 2003 pp 2124

${ }^{v}$ In current RAE language, the requirement is that a submission without textual accompaniment gives 'sufficient evidence of research in itself', and 'makes manifest' its 'research content and imperatives'. (RAE 2006: 56)

${ }^{\mathrm{V} i}$ For instance a system called DVD@ACCESS, featured on www.kenstone.net/fcp_homepage/dvd_access_link_file.html, or WebDVD: www.dvddemystified.com/webdvd/

vii This idea was partly inspired by the database technique Malcolm Le Grice used to make Chronos Fragmented, in which, as Le Grice describes it, 'images from one source are linked with others in a continuing variety; they are used, re-used and constantly transformed in the process. In other words, meanings are not locked into the initial form of the memory, but develop through juxtaposition. This is an active rather than nostalgic (or factual) notion of memory' (Le Grice 2001:). I'd say this notion of the active memory is close to the function and feeling of dreams, and it is no accident that - to me - Chronos Fragmented has a dreamlike feel.

A similar technique - the Korsakov system - has been developed by Floran Thalhofer, a computer documentary film maker from Berlin - see http://thebridge.Icc.arts.ac.uk/02 The symposium/transcripts/florian ts.php 